\title{
Comments on: Remarks and results from the use of the HAL/RAR technique in the management of patients with haemorrhoids
}

\author{
M.L. Lorentziadis
}

Although haemorrhoidectomy is regarded as the gold standard for a radical and definite treatment of haemorrhoids, the ideal surgical technique for haemorrhoidal disease is still under investigation. In the frame of minimal invasive surgery, doppler-guided HAL/RAR offers an effective alternative to other surgical treatments of symptomatic haemorrhoids. In the article "Remarks and results from the use of the HAL/RAR technique in the management of patients with haemorrhoids", the number of patients is limited and there are no patients with grade II haemorrhoidal disease, as per Goligher's classification, resistant to medical treatment. It is not clear whether an anoscopy was performed at follow-up. The period of follow-up is relatively short since the literature refers to follow-up examination periods ranging from 14 to 42 months. It is of interest that although as a procedure it has low levels of postoperative pain, it is not without complications and $100 \%$ success rate. Early complications include pain 6-15.9\%, tenesmus $24.1 \%$, pruritus $15.9 \%$, bleeding $1.2-4 \%$, dyschezia $1 \%$, mucus discharge $11.8 \%$, anal burning $20 \%$, and thrombosis of residual haemorrhoids 3\% (1.2). Late failure results in a collection of 17 articles on the HAL/RAR technique including 1.996 patients showed recurrence of prolapse $9 \%$, bleeding $7.8 \%$, and pain at defaecation $4.7 \%$ (2). The recurrence rate was higher for fourth degree haemorrhoids (range 11,1-59\%) $(2,4)$. A varying percentage $(7.1 \%-10 \%)(3,4)$ of mucosal prolapse actually concerns skin tags; skin tag-pexy is not one of the aims of THD surgery and this should be clearly explained to patients, otherwise they could mistake skin tags for haemorrhoidal prolapse. In the article mentioned above, there were no complications and no evidence of recurrence. Therefore, it is difficult to draw safe conclusions regarding this technique with the results given. According to the literature and my own experience, the HAL/RAR method is an additional technique in the surgeons' armentarium for the treatment of haemorrhoidal disease. It has the restrictions of the high-tech equipment needed for it to be performed, but it is a safe to use technique. As with all operations, it is not without complications and recurrences depending on the degree of haemorrhoidal disease and the experience of the surgeon. As a last remark, since it is a retrospective study, it would be useful to compare this technique with other cases of haemorrhoidectomy, open or closed, performed in their surgical department.

\section{References}

1. Ratto C, Donisi L, Parello A et al: Evaluation of transanal Hemorrhoidal Dearterialisation as a minimally invasive therapeutic approach to Hemorrhoids. Dis. Colon Rectum 2010; 53:803-11

2. Giordano P., Overton J., Madeddu et al: Transanal hemorrhoidal dearterialization: a systemic review. Dis. Colon Rectum 2009; 52:1665-71

3. Bursics A., Morvay K., Kupcsulik P. et al: Comparison of early and 1-year follow up results of conventional hemorrhoidectomy and hemorrhoid artery ligation: a randomized study. Int. Journal of Colorectal disease 2003. DOI 10.1007/ s00384-003-0517-9.

4. Faucheron JL., Poncet G., Voirin D. et al: Doppler-guided hemorrhoidal artery ligation and rectoanal repair (HALRAR) for the treatment of Grade IV hemorrhoids: long term results in 100 consecutive patients. Dis. Colon Rectum $2011 ; 54: 226-31$

M.L.Lorentziadis, M.D., Ph.D., FISS

Department of Surgery, Athens Medical Centre

Corresponding author: M.L.Lorentziadis, M.D., Ph.D., FISS

Department of Surgery, Athens Medical Centre, Athens, Greece

Tel: +30 210 8661465, e-mail: mlor-surg@ath.forthnet.gr 